\title{
Resumen de tesis: \\ Reformas del Estado y sindicalismo Militante: las luchas contra la privatización de los servicios públicos en los ${ }^{\prime} 90 s^{1}$
}

\author{
Ana Elisa Arriaga \\ (Universidad Nacional de Córdoba) \\ ana.elisa.arriaga@unc.edu.ar
}

$\mathrm{E}$

l estudio nació de la clásica preocupación por la relación entre conflictividad y cambio social y se nutrió del trabajo colectivo en distintos equipos de investigación en los que la dinámica regional de la protesta social fue materia de discusiones apasionadas. ${ }^{2}$ Entonces, a contrapelo de ciertos análisis sobre la adaptación o participación del sindicalismo argentino en la implementación de reformas neoliberales (Etchemendy, 2001; Murillo, 2008), en Córdoba advertíamos la presencia activa de los sindicatos como sujeto político contencioso (Gordillo et al., 2012). En ese proceso, fueron dos sindicatos de servicios los que se ganaron un lugar destacado en la escena pública local: el Sindicato del Personal de Obras Sanitarias (SiPOS) y el de Luz y Fuerza de Córdoba (SLyFC). A distancia de la imagen de la negociación desde arriba y, en contra de sus propias federaciones, estas organizaciones se convirtieron en ejemplos de una posición beligerante contra las privatizaciones. Es ahí donde se justificó nuestro interés inicial en estudiarlos.

Analizar los conflictos en torno a las privatizaciones adquirió relevancia también por el modo en que estas condensaron la naturaleza del nuevo modelo de acumulación, en términos de la enorme concentración del poder económico en la Argentina de los años 90s (Arceo y Basualdo, 1999). Y sobre todo, mostró el rol novedoso que las cúpulas sindicales asumieron perfilando su inserción como actor empresario (Ghigliani et al., 2012; Haidar, 2016, entre otros). También, puso en evidencia la implementación de la flexibilización laboral con sus nuevas tecnologías de explotación y disciplinamiento, bajo

\footnotetext{
${ }^{1}$ Tesis de Doctorado en Historia, Facultad de Filosofía y Humanidades, Universidad Nacional de Córdoba. Dirigida por la Dra. Mónica Beatriz Gordillo (CONICET- IDH- UNC). Financiada por CONICET. El tribunal evaluador estuvo conformado por la Dra. Silvia Simonassi (UNR), la Dra. Cecilia Senén González (CONICET- UBA) y la Dra. Lorena Capogrossi (CONICET- CIECS - UNC). La defensa se realizó el 30 de diciembre de 2020 y obtuvo la calificación de "Sobresaliente con recomendación de publicación".

2 Dirigidos por la Dra. Mónica Gordillo en el Centro de Investigaciones de la Facultad de Filosofía y Humanidades, UNC.
} 
amenaza de desempleo. Otra cara no menos relevante del proceso privatizador, fue el giro regresivo en la prestación de servicios, tanto en el peso creciente de las tarifas en el salario familiar, como por la falta de garantías al acceso universal de aquellos servicios esenciales para el sostenimiento de la vida.

Desde una perspectiva temporal amplia, las experiencias del SiPOS y del SLyFC se tornaron más relevantes, dado que su persistencia opositora a los proyectos privatizadores les convirtió en organizaciones promotoras y referentes de los distintos conflictos contra el avance de las reformas del Estado provincial entre 1989 y 2001. Otro rasgo compartido se advirtió en sus perfiles de liderazgo, pues sus posiciones políticas eran remitidas, tanto en la prensa local como en el discurso de sus dirigentes, a una identidad política combativa. Esa identificación se ligó a una tradición sindical conocida como sindicalismo de liberación, que emergió en Córdoba a fines de los años 60s y comienzos de los 70s, teniendo como principal referente al dirigente "lucifuercista" Agustín Tosco.

Si esos eran los rasgos similares había otros que les diferenciaban, pues a pesar de que sus campañas coexistieron en el tiempo en contextos políticos institucionales similares, sus orientaciones estratégicas fueron divergentes. También lo fueron en gran medida los resultados de sus campañas. Imposible no reparar en que la Empresa Provincial de Energía de Córdoba (EPEC) se mantuvo estatal e integrada mientras que su homóloga la Empresa Provincial de Obras Sanitarias (EPOS) fue progresivamente descentralizada y desintegrada; siendo objeto de concesión privada en varias de sus áreas, especialmente el servicio de provisión de agua potable de la Capital. Pero no estuvo en nuestra motivación explicar ese resultado, sino indagar en las transformaciones, alcances y limitaciones de la acción sindical en la historia argentina reciente, desde la perspectiva de aquellos que apostaron a sostener estrategias contenciosas.

En ese camino y durante una etapa inicial del diseño de investigación, la dinámica contenciosa y en ella la protesta resultaron categorías claves para el ingreso al tema desde la denominada agenda clásica de las teorías sobre movimientos sociales y acción colectiva (McAdam, et al., 1999; Tarrow, 1997; Tilly, 2000). Superada una etapa de reconocimiento de la dinámica de los conflictos y asumiendo las diversas revisiones al potencial heurístico del enfoque (McAdam, Tarrow y Tilly, 2005; Jasper, 2012), nuestro desafío pasó por comprender el proceso de movilización contra la privatización de los servicios públicos, la configuración del SLyFC y del SiPOS en actores colectivos específicos y las trayectorias de la contienda de manera interactiva y temporalmente dinámica. En ese sentido, la apuesta se orientó a dar cuenta del proceso de construcción de las bases organizativas e institucionales de los sindicatos estudiados, a distinguir trayectorias de demandas colectivas y a ponderar cómo se percibieron las oportunidades y amenazas, o se utilizaron determinados repertorios y no otros. En el recorrido fue adquiriendo relevancia el análisis de las capacidades organizativas (Kelly, 1998) expresadas en la estructura del grupo y su poder de movilización, visibles además en las relaciones con 
el Estado, en los modos de decidir colectivamente el horizonte de acción posible y en la acción contenciosa que finalmente pudieron desplegar ante la amenaza privatizadora.

Desde esas inquietudes, nos nutrimos de los debates conocidos como Unions Revitalización Studies preocupados por los márgenes de decisión y recursos que los sindicatos disponen para enfrentar la globalización de la producción, la acumulación flexible y su impacto en los procesos de trabajo (Voss y Sherman, 2000; Frege y Kelly, 2003; Fairbrother, 2008; Heery, 2015; Gall, 2009; entre otros). Sus aportes resultaron fundamentales en dos niveles, primero por el reconocimiento y sistematización de una serie de estrategias mediante las cuales los sindicatos han desplegado acciones más o menos exitosas para reponer su poder colectivo $\mathrm{y}$, más recientemente, esas reflexiones nutrieron debates teóricos específicos sobre los recursos de poder sindical y los modos de potenciar ese tipo particular de poder colectivo (Lévesque y Murray; 2010; Schmalz y Dörre, 2014; Wright, 2000; Dufour y Hege, 2010).

El estudio de los recursos de poder desplegados por estas organizaciones se apoyó en un corpus documental diverso, cuyo punto de partida fue una Base de Datos sobre protestas en Córdoba que recopila y sistematiza acciones noticiadas por La Voz de Interior entre 1984 y 2003. Se utilizaron además otras fuentes provenientes de la prensa periódica -Clarín, Página 12, Ámbito Financiero y La Mañana de Córdoba- revistas de actualidad política como Jerónimo, Barrial y Cuadernos Laborales y se revisaron algunos periódicos partidarios. Fue fundamental revisar documentos oficiales como leyes y decretos provinciales y nacionales, estatutos empresarios y sindicales, convenios colectivos y debates parlamentarios. La perspectiva de las organizaciones y sus referentes se trabajó a partir de documentación sindical, tanto prensa obrera -Eléctrum y Canillita- como volantes, afiches y producciones audiovisuales; además de la recopilación de testimonios orales con entrevistas a líderes y activistas sindicales desde la transición democrática hasta el 2003.

Inicialmente consideré la trayectoria de la injerencia estatal en la administración de esos servicios y valoré los cimientos del poder estructural de cada sector (Capítulo II). Allí sostengo como primera hipótesis que la provincialización de la administración de los servicios y su configuración en empresas públicas autárquicas -la EPEC y la EPOS en tanto ámbito de trabajo- favorecieron la organización sindical y la institucionalización de una determinada capacidad de negociación colectiva. El resultado de eso fue el logro de convenios colectivos propios de cada empresa, que garantizaron a estos sindicatos y sus trabajadores, su participación directa en la regulación laboral con autonomía de las cúpulas sindicales (Capítulo III). En el Capítulo IV muestro como esto resultó clave para la dinámica provincial de reformas del Estado, dada la capacidad de veto sindical a los procesos privatizadores en términos de una amplia disposición de recursos para interceder en el proceso.

Mi segunda hipótesis considera que las privatizaciones resultaron una amenaza no solo a los derechos laborales y las protecciones sociales vigentes en los convenios colectivos, sino que estos convenios devenidos en los principales bienes en disputa, 
ponían de manifiesto una durísima y prolongada batalla por el control de determinados recursos de poder sindical. Es decir, enfrentar las privatizaciones era disputar capacidad y recursos de organización sindical, aunque la distinción de estas experiencias radicará en la trayectoria histórica de esos recursos de poder remitidos al sindicalismo de liberación (Capítulos III y V). Dicha tradición sindical, entendida en los términos de Hobsbawn y Terence (2002), fue especialmente significativa en la experiencia del SLyFC que desde una posición estratégica (Womak, 2007) en la estructura productiva, había hecho del control del proceso de trabajo y la amenaza de apagón los pilares de su forma sindical para incidir en los objetivos empresarios. Esos elementos fueron recuperados y resignificados por el SiPOS hacia fines de los años 80s y por el propio SLyFC a fines de los 90s.

Como hipótesis central sostengo que la forma sindical y el perfil de liderazgo de estas organizaciones, -vistos tanto desde el diseño institucional de la representación como en los niveles de democratización en la definición de objetivos- fueron elementos fundamentales en la definición de los horizontes estratégicos a favor de defender el carácter estatal de las empresas (Capítulo V). Allí, el grado de cohesión interna en el cómo y con qué recursos fue marcando el pulso de las campañas antiprivatizadoras. Pero fue en el alcance de la solidaridad externa, como factor de poder sindical, donde se desplegó en gran medida el potencial de las luchas contra las privatizaciones de los servicios de electricidad y agua y saneamiento en Córdoba. La dinámica de la protesta mostró entonces un largo proceso de aprendizaje en el que las luchas contra las privatizaciones fueron mutando, desde el resguardo de derechos laborales como el salario y la fuente de trabajo, hasta la defensa del servicio público estatal como garante de la reproducción social (Capítulo VI).

En el balance de los hallazgos centrales de la investigación cabe señalar la versatilidad y amplitud de recursos de poder disponibles en dos organizaciones sindicales protagonistas emblemáticas de las luchas contra las reformas neoliberales en la provincia. Su liderazgo en la movilización social, tanto del SIPOS al inicio de la implementación de las reformas del Estado en 1989, como del SLyFC durante toda la década y, en particular, en las jornadas calientes del 2001 como punto de inflexión de la etapa neoliberal, permiten resignificar el rol de las organizaciones sindicales en la historia reciente.

\section{Referencias bibliográficas}

Arceo, E. y Basualdo, E. (1999). Las tendencias a la centralización del capital y la concentración del ingreso en la economía argentina durante la década del noventa. Cuadernos del Sur, 29, 29-69.

Dufour, C. y Hege, A. (2010). The Legitimacy of Collective Actors and Trade Union Renewal. Transfer. European Review of Labour and Research, 16 (3), 351-367. 
Etchemendy, S., (2001). Construir coaliciones reformistas: la política de las compensaciones en el camino argentino hacia la liberalización económica. Desarrollo Económico, 40 (160), 675-705.

Fairbrother, P. (2008). Social Movement Unionism or Trade Unions as Social Movements. Employee Responsabilities Rigths Journal, 20, 213-220.

Frege, C. y Kelly, J. (2003). Union Revitalisation Strategies in Comparative Perspective. European Journal of Industrial Relations, 9 (1), 7-24.

Gall, G. (2009). The Future of Union Organising: Building for Tomorrow. Basingstoke: Palgrave MacMillan.

Ghigliani, P.; Grigera, J. y Schneider, A. (2012). Sindicalismo empresarial: problemas, conceptualización y economía política del sindicato. RELET, 17 (27), 141-164. Recuperado de http://alast.info/relet/index.php/relet/article/view/126 (Fecha de consulta 8/9/2014).

Gordillo, M.; Arriaga, A.; Franco, M.; Medina, L.; Natalucci, A. y Solis, A. (2012). La Protesta frente a las reformas neoliberales en la Córdoba de fin de siglo. Córdoba: Ferreyra.

Haidar, J. (2016). El sindicalismo empresarial en los años 90. Una aproximación conceptual. Archivos, 4 (8), 77-96.

Heery, E. (2015). Unions and the Organising Turn: Reflections after 20 Years of Organising Works. The Economic and Labour Relations Review, 26 (4), 545-560.

Hobsbawm, E. y Terence, R. (2002) La Invención de la Tradición. Barcelona: Crítica.

Jasper, J. (2012) ¿De la estructura a la acción? La teoría de los movimientos sociales después de los grandes paradigmas. Sociológica, 27 (75), 7-48.

Kelly, J. (1998). Rethinking Industrial Relations. London: Routledge.

Lévesque, Ch. y Murray, G. (2010). Understanding Union Power: Resources and Capabilities for Renewing Union Capacity. ETUI, The European Trade Union Institute, 16 (3), 333-350.

McAdam, D.; McCarthy, J. y Zald, M. (1999). Movimientos sociales: Perspectivas comparadas. Oportunidades politicas, estructuras de movilización y marcos interpretativos culturales. Madrid: Istmo.

McAdam, D.; Tarrow, S. y Tilly, Ch. (2005). Dinámica de la contienda política. Barcelona: Hacer Editorial.

Murillo, M. V. (2008). Sindicalismo, coaliciones partidarias y reformas de mercado en América Latina. Buenos Aires: Siglo XXI Editores.

Schmalz, S. y Dörre, K. (2014). Der Machtressourcenansatz: Ein Instrument zur analyse gewerkschaftlichen Handlungsvermögens. Industrielle Beziehungen, 21 (3), 217-237.

Tarrow, S. (1997). El poder en movimiento. Los movimientos sociales, la acción colectiva y la política. Madrid: Alianza.

Tilly, Ch. (2000). Acción Colectiva. Apuntes de Investigación del CECYP, 6, 9-31.

Voss, K., y Sherman, R. (2000). Breaking the Iron Law of Oligarchy: Union Revitalization in the American Labor Movement. American Journal of Sociology, 106 (2), 303-349. 
Womak, J. (2007). Posición estratégica y fuerza obrera. Hacia una nueva historia de los movimientos obreros. México: Fondo de Cultura Económica.

Wright, E. O. (2000). Working-Class Power, Capitalist-Class Interests, and Class Compromise. American Journal of Sociology, 105 (4), 957-1002

Para citar este resumen:

Arriaga, Ana Elisa (2021). Resumen de tesis: "Reformas del Estado y sindicalismo Militante: las luchas contra la privatización de los servicios públicos en los '90s". Anuario de la Escuela de Historia Virtual, 19, 144-149. 